\title{
Analysis of sequential rule mining for energy conservation
}

Dr. Dhanasekaran $\mathbf{K}^{1}$, Prakash K Sonwalkar ${ }^{2}$
${ }^{1}$ Department of Computer Science and Engineering, Jain College of Engineering, Belgaum,
Karnataka, India
${ }^{2}$ Department of Computer Science and Engineering, Jain College of Engineering, Belgaum,
Karnataka, India

\begin{abstract}
The energy requirement for household usage in residential buildings has increased rapidly in recent years. The storage method, user behaviour, and transmission method have major impact on the quantity and quality of energy consumed in daily scenario. This paper presents existing techniques with a research focus on improving energy efficiency. The goal of this research effort is to analyze the research gap to discover efficient method for object tracking and real-time monitoring of household items through identification of effective use of alternative sources of energy and improper use of energy using sequence patterns. The monitoring of the different states of moving objects poses a challenge which needs to be addressed in real-life applications to improve communication among system components and the end users. This paper presents proposed model to address the energy issues and discusses major advantages and limitations of existing methods that use data mining for energy conservation.
\end{abstract}

Keywords: Energy management, data science, sequential rule mining, data mining, computational technologies

Corresponding Author: Dr. K. Dhanasekaran

\section{INTRODUCTION}

Energy management is currently attracting a great deal of attention among research communities. Nowadays, technologies are available to collect, and store the vast amount of data. The use of data science techniques can enable analysis and exploitation of such data in a better way. Sequential rule mining plays a very important role in applications such as disaster management, network security, water management, traffic analysis, land usage monitoring, weather monitoring, power usage monitoring, solid waste management and many others.

This paper presents discussion of existing approaches in the field of energy management that applies data mining technique such as sequential rule mining. Furthermore, research possibilities are analyzed to address the most serious problems faced by researchers in the field of energy monitoring. This work provides an insight into the major challenges and opportunities that will arise in the future due to the multidisciplinary nature of the energy conservation.

Major issues and challenges in energy conservation:

\section{Issues:}

- Sensors require power for various operations without power loss.

- Even if user is idle, components use energy. 
- Energy network should possess abilities such as network management, and auto-failure recovery.

- Large Network would require thousands of sensors which lead to costlier network establishment.

- Radio signal range of sensor node is critical for ensuring network connectivity and software should be hardware independent, should consume less energy.

- Complex operating system may cause hardware issues such as scheduling, pre-empting and networking at lower level.

- Primary causes of energy waste such as collision, packet overhead, and idle states are found at the MAC layer.

- Network topology in WSN would change constantly. It would result in imprecise routing information.

- Eavesdropping may occur if confidentiality is not being maintained.

- Data collected from different environments may be redundant.

\section{Challenges:}

- Designing and developing an efficient hardware and software protocols.

- Providing self-management capability to the systems.

- Deployment of field programmable gate arrays to reduce power consumption.

- Selecting appropriate Operating System (OS) that supports easy programming.

- Long packets will be practically challenging while trying to reduce power and it is difficult to implement forward error control technique to save power, because, it requires high power.

- Right use of bandwidth in traffic prone sensor network to avoid slow delivery of packets. Even though multi-hops can reduce the energy consumption, the bandwidth overhead may limit the effective use of multi-hops.

- Designing of scalable, flexible, and durable wireless sensor network architecture to provide good quality of service with easy addition or removal of nodes.

- Achieving better security in critical systems.

- Integrity of data needs to be maintained to protect data from different types of threats.

- Sensor network do not have a fixed set of communication protocols to transfer data, it emphasizes the need to maintain the balance between processing speed and communication bit rates.

Dealing with some of these challenges to address certain critical issues is a key to ensure sustainability in energy sector. The system architecture proposed to improve efficiency is shown in Figure 1. It illustrates the use of sequential rule mining for energy conservation.

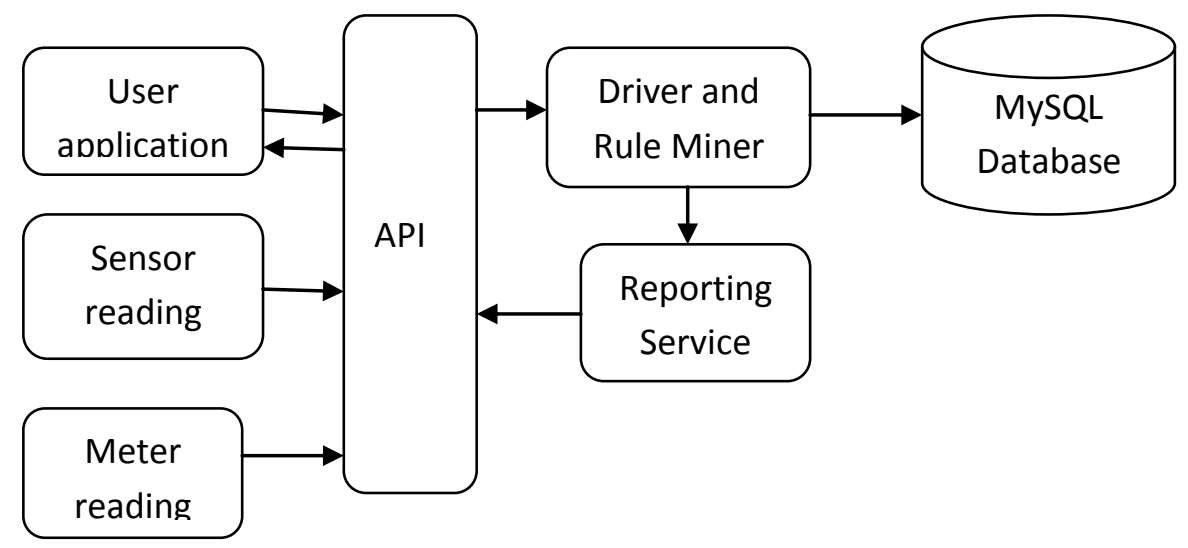

Fig 1: System architecture 
Since many energy consuming devices use energy in residential building, it is necessary to understand the causal factors that influence energy consumption. In this work, we study and analyze the existing techniques that use rule mining to derive the usage pattern from data set.

\section{ANALYSIS OF EXISTING METHODS}

Object tracking plays a vital role in many real-life applications. In wireless sensor networks, energy is one of the most important factors for tracking applications. A prediction based energy-efficient tracking method discussed in [1] focused on using sequential patterns to achieve considerable reductions in the energy while maintaining tolerable missing rate levels.

This method not only aimed to decrease the missing rate through prediction of future movements of dynamically moving objects, but also has tried to reduce the energy consumption by sinking the number of nodes. That is, the majority of the sensor nodes put in sleep mode in order to minimize the communication disbursement.

The predication-based tracking techniques that use sequence patterns can provide the ability to predict the next required level of actions, use of alternative energy sources, or state changes of components like sensors, Micro Controller Unit (MCU) etc.

Most of the existing works on object tracking that use sequence patterns have aimed to generate hidden patterns while network monitoring takes place according to criteria such as temperature, medical data load. Some of the authors have proposed approaches which generate patterns about behaviour of sensors. Sensor association rules proposed in one work has tried to capture the temporal correlations between the sensor nodes in a wireless sensor network. The following section describes existing energy management schemes to analyse the feasibility of developing a new framework based on sequential rule mining.

A prediction based energy efficient tracking technique utilizes sequential patterns to predict the future movements of objects in a wireless sensor network. The sequential patterns are evaluated to make accurate predictions. In this section, Table 1 presents insights into the existing methods.

Table 1 Existing methods

\begin{tabular}{|c|c|c|c|}
\hline $\begin{array}{l}\text { Method/ } \\
\text { Framework/ } \\
\text { Technique }\end{array}$ & Authors & Advantages & Limitations \\
\hline $\begin{array}{l}\text { Prediction based } \\
\text { energy efficient } \\
\text { tracking }\end{array}$ & $\begin{array}{l}\text { J Joseph Ignatious } \\
\& \\
\text { Dr.S.Abraham } \\
\text { Lincon }\end{array}$ & $\begin{array}{l}\text { a)Decreasing the missing- } \\
\text { rate by predicting } \\
\text { movements of moving } \\
\text { objects. } \\
\text { b)Reducing the Energy } \\
\text { consumption by sinking } \\
\text { the number of nodes that } \\
\text { join in tracking, } \\
\text { minimizing the } \\
\text { communication } \\
\text { disbursement. }\end{array}$ & $\begin{array}{l}\text { a)Each sensor node } \\
\text { covers a range of } \\
15 \mathrm{~m} \text {. } \\
\text { b)Object chooses a } \\
\text { random path. } \\
\text { c) The ratio of the key } \\
\text { paths to the random } \\
\text { paths is } 3: 1 .\end{array}$ \\
\hline $\begin{array}{lr}\text { A rule-based } \\
\text { approach using } \\
\text { concepts and } \\
\text { techniques }\end{array}$ & $\begin{array}{l}\text { Suan Khai Chong } \\
\text { et al. }\end{array}$ & $\begin{array}{l}\text { a)Extracting } \\
\text { environmental information } \\
\text { for controlling sensor } \\
\text { operations. }\end{array}$ & $\begin{array}{l}\text { a) Scalability has not } \\
\text { been given much } \\
\text { attention. Hence this } \\
\text { approach cannot be }\end{array}$ \\
\hline
\end{tabular}




\begin{tabular}{|c|c|c|c|}
\hline & & $\begin{array}{l}\text { b)A generic framework } \\
\text { aimed to prolong network } \\
\text { lifetime based on context } \\
\text { awareness, targeting } \\
\text { energy conservation at the } \\
\text { sensor node level } \\
\text { c)Highly correlated rules } \\
\text { to learn and discover rules } \\
\text { to efficiently regulate } \\
\text { sensing. }\end{array}$ & $\begin{array}{l}\text { suitable for dense } \\
\text { wireless sensor } \\
\text { network that consists } \\
\text { of large number of } \\
\text { nodes. }\end{array}$ \\
\hline $\begin{array}{l}\mathrm{LEACH} \\
\text { protocol }\end{array}$ & Heinzelman et al. & $\begin{array}{l}\text { a)Allows nodes in a sensor } \\
\text { network to organize in the } \\
\text { form of set of cluster heads } \\
\text { based on probability } \\
\text { measure. } \\
\text { b)Performs randomized } \\
\text { rotation for high-energy } \\
\text { cluster-head selection } \\
\text { among sensors in a cluster. } \\
\text { It can avoid drain on a } \\
\text { single sensor. }\end{array}$ & $\begin{array}{l}\text { a)To enhance network } \\
\text { lifetime, local data } \\
\text { fusion is needed } \\
\text { which allows only } \\
\text { aggregated } \\
\text { information to the } \\
\text { source. }\end{array}$ \\
\hline $\begin{array}{l}\text { Data granularity } \\
\text { control } \\
\text { approach }\end{array}$ & $\begin{array}{l}\text { Hefeeda M \& } \\
\text { Bagheri M }\end{array}$ & $\begin{array}{l}\text { a)It can reduce the amount } \\
\text { of data communicated in a } \\
\text { network and can improve } \\
\text { network lifetime. }\end{array}$ & $\begin{array}{l}\text { a) Data granularity } \\
\text { emphasizes the need } \\
\text { for selecting only } \\
\text { appropriate data with } \\
\text { good accuracy, for } \\
\text { example, smart health } \\
\text { care application would } \\
\text { require accurate } \\
\text { values from sensor } \\
\text { nodes }\end{array}$ \\
\hline $\begin{array}{l}\text { Big data driven } \\
\text { smart energy } \\
\text { management }\end{array}$ & Kaile Zhou et al. & $\begin{array}{l}\text { a)Studied big data driven } \\
\text { smart energy management. } \\
\text { b)Discussed the sources } \\
\text { and characteristics of } \\
\text { energy big data. } \\
\text { c)Proposed a process } \\
\text { model of big data driven } \\
\text { energy management. }\end{array}$ & $\begin{array}{l}\text { a)The volume of data } \\
\text { and complex } \\
\text { structures and forms } \\
\text { b)Weather data such } \\
\text { as the angle of the } \\
\text { sun, wind speeds and } \\
\text { temperature }\end{array}$ \\
\hline $\begin{array}{l}\text { Energy } \\
\text { consumption } \\
\text { simulation } \\
\text { framework for } \\
\text { WSN }\end{array}$ & $\begin{array}{l}\text { Alexander Von } \\
\text { Bodisco \& Phuoc } \\
\text { Tran-Gia }\end{array}$ & $\begin{array}{l}\text { a)Focused on the } \\
\text { implementation and } \\
\text { interfaces. } \\
\text { b)Provided the } \\
\text { possibility to compare } \\
\text { sensor nodes, protocols, } \\
\text { and applications by } \\
\text { simulating } \\
\text { the energy consumption of } \\
\text { networks with different } \\
\text { traffic load, routing }\end{array}$ & $\begin{array}{l}\text { a)Focused on the } \\
\text { shorter routes. } \\
\text { b)Need to focus on } \\
\text { battery models to } \\
\text { assess the capability } \\
\text { of the routing } \\
\text { protocol. }\end{array}$ \\
\hline
\end{tabular}




\begin{tabular}{|c|c|c|c|}
\hline & & protocol, and topologies. & \\
\hline $\begin{array}{l}\text { Energy } \\
\text { efficiency } \\
\text { mechanisms } \\
\text { using mobile } \\
\text { Node }\end{array}$ & $\begin{array}{l}\text { Teddy Mantoro et } \\
\text { al. }\end{array}$ & $\begin{array}{l}\text { a)Focused on optimizing } \\
\text { energy efficiency by } \\
\text { deploying a mobile base } \\
\text { station. } \\
\text { b)Aimed to collect } \\
\text { data without using } \\
\text { gateway sensors. } \\
\text { c)Reduced bottlenecks in } \\
\text { multihop networks. } \\
\text { d)Proposed a network } \\
\text { structure that collects data } \\
\text { using mobile node based } \\
\text { on double Fermat's spiral } \\
\text { model. }\end{array}$ & $\begin{array}{l}\text { a)Sensor nodes have } \\
\text { only finite energy } \\
\text { reserves from a } \\
\text { battery, and mobile } \\
\text { base station is set to } \\
\text { move along a fixed } \\
\text { path, } \\
\text { it emphasizes the need } \\
\text { to improve energy } \\
\text { management. } \\
\text { b)Network coverage, } \\
\text { packet collision, Idle } \\
\text { listening, multihop } \\
\text { bottlenecks, and noise } \\
\text { distortion would be } \\
\text { the other limiting } \\
\text { factors. }\end{array}$ \\
\hline $\begin{array}{l}\text { A technique for } \\
\text { parallel share- } \\
\text { frequent sensor } \\
\text { pattern mining }\end{array}$ & $\begin{array}{l}\text { Md.Mamunur } \\
\text { Rashid et al. }\end{array}$ & $\begin{array}{l}\text { a)Proposed a behavioural } \\
\text { pattern called share- } \\
\text { frequent sensor patterns. } \\
\text { b)Developed a parallel } \\
\text { share-frequent sensor } \\
\text { pattern tree. This tree is } \\
\text { constructed at each local } \\
\text { node independently and } \\
\text { then merges the locally } \\
\text { generated candidate } \\
\text { patterns. }\end{array}$ & $\begin{array}{l}\text { a)WSNs generate } \\
\text { huge amount of data } \\
\text { in the form of streams. } \\
\text { b) The limited } \\
\text { resources, and the } \\
\text { distributed nature } \\
\text { brings new challenges. } \\
\text { c)Mining useful } \\
\text { knowledge requires } \\
\text { efficient technique. } \\
\text { Merging is costlier } \\
\text { Operation. }\end{array}$ \\
\hline $\begin{array}{l}\text { Analyzing the } \\
\text { impact of the } \\
\text { hybridized } \\
\text { stream } \\
\text { behaviour } \\
\text { and intersection } \\
\text { type using } \\
\text { simulation }\end{array}$ & $\begin{array}{l}\text { Samia } \text { Boubaker } \\
\text { et al. }\end{array}$ & $\begin{array}{l}\text { a)Developed instantaneous } \\
\text { energy consumption and } \\
\text { emission models. } \\
\text { b)Identified that a } \\
\text { roundabout can obtain } \\
\text { more environmental } \\
\text { improvements and energy } \\
\text { reductions. }\end{array}$ & $\begin{array}{l}\text { Vehicle's energy } \\
\text { consumption and } \\
\text { emissions. }\end{array}$ \\
\hline $\begin{array}{l}\text { Performance- } \\
\text { Aware Energy } \\
\text { Saving } \\
\text { Mechanism }\end{array}$ & Hai Nguyen et al. & $\begin{array}{l}\text { Developed performance- } \\
\text { aware energy saving } \\
\text { mechanism to address the } \\
\text { issue associated with the } \\
\text { link speed reduction. }\end{array}$ & $\begin{array}{l}\text { a)It requires higher } \\
\text { level of complexity } \\
\text { and } \\
\text { higher performance in } \\
\text { interconnection } \\
\text { networks. } \\
\text { b)It relies on the } \\
\text { contribution of link } \\
\text { components. } \\
\text { The Link speed }\end{array}$ \\
\hline
\end{tabular}




\begin{tabular}{|c|c|c|c|}
\hline & & & $\begin{array}{l}\text { reduction incurs an } \\
\text { increase in average } \\
\text { packet latency. }\end{array}$ \\
\hline $\begin{array}{l}\text { Remote sensing } \\
\text { methods for } \\
\text { power line } \\
\text { corridor }\end{array}$ & $\begin{array}{l}\text { Leena Matikainen } \\
\text { et al. }\end{array}$ & $\begin{array}{l}\text { a)Focused on monitoring } \\
\text { of both power line } \\
\text { components and } \\
\text { vegetation. } \\
\text { b)Discussed various } \\
\text { approaches to enable } \\
\text { uninterrupted distribution } \\
\text { of electricity through } \\
\text { effective monitoring. }\end{array}$ & $\begin{array}{l}\text { Data integration } \\
\text { would limit the } \\
\text { capabilities of } \\
\text { automatic extraction } \\
\text { of power line data. }\end{array}$ \\
\hline $\begin{array}{l}\text { Rule-based } \\
\text { home energy } \\
\text { management } \\
\text { using Rete } \\
\text { algorithm }\end{array}$ & \begin{tabular}{|l|} 
Tomoya \\
Kawakami et al.
\end{tabular} & $\begin{array}{l}\text { a)Proposed a rule-based } \\
\text { Home energy management } \\
\text { system using the Rete } \\
\text { Algorithm. } \\
\text { b)Rete algorithm is a } \\
\text { pattern matching algorithm } \\
\text { for if-then rules. } \\
\text { c)Rule reduction is being } \\
\text { performed by distributing } \\
\text { the load to nodes for } \\
\text { managing energy in } \\
\text { network. }\end{array}$ & $\begin{array}{l}\text { a)Existing systems } \\
\text { assume if-then rules. } \\
\text { b)Categorization of } \\
\text { nodes is needed in } \\
\text { large scale network. }\end{array}$ \\
\hline
\end{tabular}

Liang Zhao et al. [13] presented the application of data mining in building energy consumption data. This paper focused on prediction of energy consumption, fault diagnosis, and optimal operation. The data processing method proposed in this paper classifies abnormal data. In order to deepen users' understanding of data, this method performs recognition and processing of abnormal data. AminNaseri and Soroush [14] demonstrated that the data mining methods achieved significant improvement in terms of prediction accuracy. In this piece of research work, author used a hybrid neural network model in combination with cluster analysis.

Janina Popeanga [15] tried to demonstrate the application of data mining techniques with respect to time series analysis in energy domain. The rapid growth of smart metering technology results in generation of huge amount of energy data which makes it difficult to analyze relationships within time series data. Hence, it is necessary to propose new methods to find useful patterns from those data.

A k-nearest neighbour based text classification in [16] has focused on extracting useful information from text data and aimed to provide insights about plant disease control and management to guide farmers. Furthermore, a task-oriented information extraction discussed in [17] used unstructured data. A dynamic programming technique adopted in this work finds relevant patterns from long sequences and attempted to find matching sequences to identify factors that affect correctness of information. This paper focused on context-based extraction for extracting safety information.

Sensor association rules are usually used to generate patterns to the sensor nodes. The patterns that are generated can be used to develop the quality of service in a wireless sensor network, providing an opportunity to predict the source of missed objects. 


\section{CONCLUSION}

In this research, it was observed that when number of sensor nodes increased, dealing with reliability, scalability, integrity, and errors becomes a challenging task. Hence experimental method should find the right network area and monitoring region to specify these sensor nodes within a Wireless Sensor Network (WSN) area. The speed of tracking object should need to be measured in order to provide real time data service.

If we assume that any object may select a random path, the ratio of the selected paths to the random paths should be appropriately set with suitable values. The object tracking component could send location of moving object to the application. The comparative analysis should consider the power used by components like MCU, Router, Switches, Hub, and MPU etc. For experimental purpose, we can consider metrics like total energy consumption rate, missing object rate, supply rate, and sleeping object rate. This paper presents analysis of sequential data mining techniques for energy conservation. In future, the integration of map data with automatic extraction technique will be studied.

\section{REFERENCES}

[1] J.Joseph Ignatious et al., A Prediction based Energy-Efficient Tracking Method in Sensor Networks, American International Journal of Research in Science, Technology, Engineering \& Mathematics, 5(2), pp.111-115,2013-2014.

[2] Suan Khai Chong, Mohamed Medhat Gaber, Shonali Krishnaswamy, Seng Wai Loke, Energy conservation in wireless sensor networks: a rule-based approach, Knowl Inf Syst, vol 28, pp 579-614, 2011.

[3] Heinzelman WR, Chandrakasan A, Balakrishnan H, Energy-efficient communication protocol for wireless microsensor networks. In: $33^{\text {rd }}$ Annual Hawaii international conference on system sciences.Maui, pp 2-12,2000.

[4] Hefeeda M, Bagheri M, Wireless sensor networks for early detection of forest fires. In: IEEE International conference on mobile adhoc and sensor systems. Pisa, pp 1-6,2007.

[5] Kaile Zhou, Chao Fu, Shanlin Yang, Big data driven smart energy management: From big data to big insights, Renewable and Sustainable Energy Reviews, vol 56, pp 215-225,2016.

[6] Alexander Von Bodisco \& Phuoc Tran-Gia, Energy Consumption Framework for Wireless Sensor Networks, Research Gate, pp 1-7,2007.

[7] Teddy Mantoro, Media Anugerah Ayu, Wendi Usino, Energy Efficiency Mechanisms using Mobile Node in Wireless Sensor Networks, ResearchGate, pp 537-550,2012.

[8] Md. Mamunur Rashid, Iqbal Gondal and Joarder Kamruzzaman, A technique for parallel sharefrequent sensor pattern mining from wireless sensor networks, In: Proceedings of the $14^{\text {th }}$ International Conference on Computational Science, vol. 29, pp.124-133,2014.

[9] Samia Boubaker, Ferid Rehimi, and Adel Kalboussi, Impact of intersection type and a vehicular fleet's hybridization level on energy consumption and emissions, Journal of traffic and transportation engineering, vol.3, pp. 253-261,2016. 
[10] Hai Nguyen, Daniel Franco, and Emilio Luque, Performance-aware energy saving mechanism in interconnection networks for parallel systems, In: $14^{\text {th }}$ International Conference on Computational Science, vol.29, pp.134-144,2014.

[11] Leena Matikainen, Matti Lehtomaki, Eero Ahokas, Juha Hyyppa, Mika Karjalainen, Anttoni Jaakkola, Antero Kukko, Tero Heinonen, Remote sensing methods for power line corridor surveys, ISPRS Journal of Photogrammetry and Remote Sensing, vol.119, pp.10-31,2016.

[12] Tomoya Kawakami, Naotaka Fujita, Tomoki Yoshihisa, and Masahiko Tsukamoto, An evaluation and implementation of rule-based home energy management system using the Rete Algorithm, The scientific world journal, vol.2014, pp.1-8,2014.

[13] Liang Zhao, Jili Zhang, Chongquan Zhong, The application of data mining technology in building energy consumption data analysis, International Journal of Computer and Information Engineering, vol.10, no.1, pp.81-85,2016.

[14] M.R.Amin-Naseri, A.R.Soroush, Combined use of unsupervised and supervised learning for daily peak load forecasting, Journal of energy conversion and management, vol.49,pp.1302-1308,2008.

[15] Janina Popeanga, Data mining smart energy time series, Database systems journal, vol.6, pp.1422,2015 .

[16] Dhanasekaran K, Rajeswari R, Extended text feature classification with information extraction, International Journal of Applied Engineering Research, vol.10, no.29, pp.22671-22676, 2015.

[17] Kuttiyapillai, D. And Rajeswari, R. (2015) 'A method for extracting task-oriented information from biological text sources’, Int. J. Data Mining and Bioinformatics, vol.12, no.4, pp.387-399. 